\title{
Assessment of Patellar Tendinopathy in Professional Basketball Players using Algometry
}

\section{Valoración de la tendinopatía rotuliana en jugadores profesionales de baloncesto mediante algometría}

\author{
Josep C. Benítez-Martínez ${ }^{1}$ Pablo Martínez-Ramírez ${ }^{2}$ Fermín Valera-Garrido ${ }^{3}$ Francesc Medina-Mirapeix ${ }^{4}$ \\ ${ }^{1}$ Department of Physical Therapy, Universitad de València, València, Spain \\ ${ }^{2}$ ACB team, Valencia Basket Club, València, Spain \\ 3 Universidad CEU San Pablo, MVClinic, Madrid, Spain \\ Address for correspondence Josep C. Benitez-Martinez, PT, PhD, \\ Departamento de Fisioterapia, Universitat de València, Calle Gascó \\ Oliag, 5 - 46010, València, Spain (e-mail: josep.benitez@uv.es).
}

${ }^{4}$ Department of Physical Therapy, Universidad de Murcia, Murcia, Spain

Rev Fisioter Invasiva 2019;2:2-8.

\begin{abstract}
Keywords

- pain

- tendon lesions

- VISA-P

- pain pressure threshold

- patellar tendinopathy

Introduction Palpation tenderness is one of the clinical signs used in the diagnosis of patellar tendinopathy (PT). Despite the widespread use of pain pressure thresholds (PPTs) for assessment purposes, it is unknown whether other variables may influence the results of this test and its precision to discriminate between knees with and without PT.

Objective To identify the discriminative accuracy of PPTs as a diagnostic test of PT in professional basketball players, used both in an isolated manner and in combination with other tests.

Material and Methods An observational study with professional basketball players in which the main variable measured was the PPT, and the secondary variables were the Victorian Institute of Sport Assessment, Patellar tendon (VISA-P) questionnaire and the visual analogue scale (VAS). Age, weight and height were gathered as potential covariates. The receiver operating characteristic (ROC) curve was constructed with the data of the area under the ROC curve (AUC), used to determine the precision of the PPT applied on its own or combined with other secondary variables and covariates.

Results In total, 146 patellar tendons of 73 players were analyzed. When analyzing the differences between the PPT of healthy tendons and those with PT, differences were found between the dominant leg and the non-dominant leg. Regarding the cut-off points, the most precise discrimination of a tendon with PT was $8.8 \mathrm{~kg} / \mathrm{cm} 2$ for an isolated PPT test and $14 \%$ for its combination with the VAS.

Conclusions This study shows the effectiveness of combining the data from the PPT and the VAS scores. Therefore, both tests should be used for the assessment of PT in professional basketball players, as this combination increases the discriminatory accuracy. Furthermore, these tests are easily applied in clinical practice.

Resumen

Introducción La sensibilidad del tendón a la palpación es uno de los signos clínicos utilizados en el diagnóstico de TR. A pesar del amplio uso de los umbrales de dolor a la presión (UDP) en la valoración, se desconoce si otras variables pueden influir en los resultados de este test y su precisión para discriminar entre rodillas con o sin TR.
\end{abstract}

DOI https://doi.org/ $10.1055 / \mathrm{s}-0039-1681104$. ISSN 2386-4591.
Copyright $\odot 2019$ by Thieme Revinter Publicações Ltda, Rio de Janeiro, Brazil
License terms

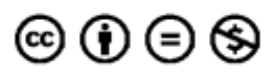




\author{
Palabras clave \\ - tendinopatía \\ rotuliana \\ - dolor \\ - lesiones del tendón \\ - VISA-P \\ - umbral del dolor a la \\ presión
}

\begin{abstract}
Objetivos Identificar la exactitud discriminatoria del UDP como prueba diagnóstica de la tendinopatía rotuliana (TR) en jugadores profesionales de baloncesto, bien de forma aislada o en combinación con otros tests.

Material y Métodos Estudio observacional con jugadores profesionales de baloncesto a los que se les midió como variable principal sus UDP, y como variables secundarias la Visa-P y EVA, considerando la edad, peso y altura y como potenciales covariables. Se construyó la curva característica operativa del receptor (COR) con los datos del área debajo la curva (ADC), utilizados para determinar la precisión del UDP aislado, o combinado con otras variables secundarias y covariables.

Resultados Se realizó el análisis de 146 tendones rotulianos de 73 jugadores. Al analizar las diferencias en el UDP entre tendones sanos y con TR, se encontraron diferencias entre la pierna dominante y no dominante. En los puntos de corte la discriminación más precisa de un tendón con TR fueron de $8,8 \mathrm{~kg} / \mathrm{cm}^{2}$ para la prueba de UDP aislada y del $14 \%$ para su combinación con EVA.

Conclusiones Este estudio muestra que la combinación de los datos del UDP y EVA, son eficaces y por tanto deberían ser usados en la valoración de la TR de jugadores profesionales de baloncesto, ya que su combinación aumenta la exactitud discriminatoria y son fácilmente aplicables en la práctica clínica.
\end{abstract}

\section{Introduction}

The presence of disorders in the relationship between the structure and physiology of the tendon can lead to varied clinical presentations for tendinopathies, characterized by pain and tendon dysfunction. Moreover, it is considered that the increase of different sensitizing substances in the tendon may significantly contribute towards tendinopathy. ${ }^{1}$ As such, this increase of sensitizing substances is directly related to the response to certain exploratory tests, such as pain in response to pressure or a decreased pain pressure threshold.

Clinically, patellar tendinopathy (PT) often presents as a localized pain in the proximal insertion of the patellar tendon on the patella. Despite the fact that its prevalence is difficult to determine (as those who suffer from PT can usually continue training and competing ${ }^{2}$ ), a study performed with young amateur athletes demonstrated that the prevalence of PT varies across different sports, showing that basketball players have a prevalence of $31.9 \%$. $^{3-5}$

Among professional basketball players, pain at the level of the patellar tendon can lead to limitations in performance during training, which means that many players have to decrease their level of training and competition during extended periods of time, leading to a loss of physical capacity. ${ }^{4}$ Physiotherapy interventions currently include prevention measures, as well as an early diagnosis and treatment of PT. ${ }^{6}$ Palpation tenderness is one of the most common signs used for the diagnosis of PT, although it does not offer clinicians diagnostic certainty, as opposed to ultrasound examinations. ${ }^{7}$ However, recent studies show ${ }^{8}$ that a pressure of $3.75 \mathrm{~kg}$ can be used as a discriminatory test between non-professional players who are healthy and those with PT.

Most studies on the validity and reliability of pain pressure thresholds (PPTs) have been performed with young amateur players and, on occasion, athletes; ${ }^{5,8,9}$ however, it is unknown whether these data can be extrapolated to professional basketball players to determine the presence of PT or to what extent PPTs may be useful for the diagnosis of this population. In addition, despite the wide use of PPTs for assessment, it is unknown whether these data can be extrapolated to professional basketball players to determine the presence of PT or to what extent PPTs can be useful as a diagnostic measure in this population. Furthermore, despite the extensive use of PPT for assessment purposes, it is unknown whether other variables may influence the results of this test and its accuracy to discriminate between knees with and without PT.

The main goal of this study was to identify whether the PPT can be used as a diagnostic test of PT in professional basketball players, either on its own or combined with other tests. Our hypothesis is that the PPT test has acceptable discriminatory accuracy for the diagnosis of PT and that this accuracy improves if other significant covariates are considered.

\section{Material and Methods}

\section{Study Design and Participants}

An observational study took place among professional basketball players in the first division of the Spanish league. The study was presented to the Ethics Committee for Human Studies of the Universitat de València and was approved with approval number H1456389710571. The study was performed during the 2015/2016 basketball season, between November and May. All teams belonging to the Association of Basketball Clubs (ACB, in the Spanish acronym)-Spanish professional league-were verbally informed of the study and invited to participate. The players were recruited by the physiotherapists on their team with both the knowledge and 
consent of their trainer. After discussing the study with the respective medical teams and team trainers, 8 teams, with a total of 16 players, agreed to participate. The inclusion criteria consisted of: being a professional player over the age of 18 and being an active player at the time of the study. The exclusion criteria included players with a systemic illness; those who had undergone knee surgery in the past; those who had received invasive physiotherapy during the previous 3 months or those who had taken antiinflammatory medication during the previous 24 hours. Also, players who were unable to communicate in Spanish or English were excluded. All the selected players were informed verbally and in writing of the study proposal and invited to participate voluntarily. All participants signed an informed consent.

The players were diagnosed with PT using the following diagnostic criteria ${ }^{8}: 1$ ) previous history of pain in the patellar tendon during sports activities or after the same, at least during the previous 3 months; 2) tenderness to pressure applied to the patellar tendon at the inferior pole of the patella; and a VISA-P score of 80 or below.

\section{Study Variables}

The data collection was performed by two experienced physical therapists between 12 and 24 hours before the regular league game.

\section{Pain Pressure Threshold}

The PPT of the patellar tendons of the players was measured using an algometer (Pain Test-Model FPK 40; Wagner Instruments, Greenwich, CT). The device was applied in the tendon via its rubber disk with a surface of $1 \mathrm{~cm}^{2}$. All the algometry tests were performed by the same examiner (PMR), who was blinded regarding the VISA-P scores and the visual analogue scale (VAS) results, which were taken by another examiner (JBM). The PPT scores were measured with the players lying in a supine position with a slight knee flexion $\left(30^{\circ}\right)$ maintained with the support of a cushion placed in the popliteal space. Once the examiner located the site where the player referred greater sensitivity or pain to palpation, he fixated the patella with one hand from the superior pole and applied pressure with the algometer, progressively increasing the compression by $0.1 \mathrm{~kg} / \mathrm{s}$ increments until the player began feeling pain, at which point the subject lifted his hand, and the examiner stopped applying compression, recording the amount of pressure applied at that time. Two measurements were performed at each point, separated by $60 "$, after which the mean of the two measurements was recorded.

\section{VAS}

All players were asked which was the maximum level of pain they had experienced during basketball training the previous week, which was registered using an 11 point (0-10) VAS. The players were taught the scale with two faces, a happy face on one side and a sad face on the other end. The scale is calibrated on the reverse side with a 0 (happy face) and a 10 (sad face).

\section{VISA-P}

The Victorian Institute of Sport Assessment, Patellar tendon (VISA-P) questionnaire can be used to quantify the symptoms, function and capacity to perform sports activity in those who suffer PT. ${ }^{10}$ The player must respond to a series of questions which assesses their ability to perform certain activities. Each question is assessed from 0 to 10 points, whereby 10 is complete functionality and 0 is total incapacity. The total sum of the different activities on the scale gives a final score of the player's functional score, in which 100 is the maximum possible score. This questionnaire was not designed for the diagnosis of PT; however, it is a useful tool to identify the clinical severity as well as the symptoms, function and participation in sports. ${ }^{3,4}$ For the Spanish players, we used the Spanish version of the VISA-P, ${ }^{11}$ while for the remaining players, the English version was used.

Furthermore, 3 other covariates were measured:1) age (years); 2) height (cm); and 3) weight ( $\mathrm{kg})$.

\section{Statistical Analysis}

The $t$-test for independent samples was used, or the U MannWhitney test for examining the differences between groups of tendons on the dominant side and the non-dominant side in relation to the presence of absence of PT. Multiple linear regression models were used to evaluate the covariates associated with the PPT scores of both the dominant and non-dominant sides. Both models were produced by the retroactive method and used the criteria of $p<0.10$ for the exclusion of the model.

The receiver operating characteristic (ROC) curve was constructed with the data of the area under the ROC curve (AUC) used to determine the precision of the PPT on its own or combined with the remaining covariates. To determine the combined score, the predicted probability of being able to discriminate between tendons with PT and healthy tendons was calculated using logistic regression models (full model), in which the dependent variable was PT (yes/no), and the independent variables were the PPT test and the remaining covariates. Furthermore, other combined scores were considered using only a partial number of covariates and the AUC was used to assess their discriminatory presence. According to previous authors, ${ }^{12}$ an AUC $>0.7$ was used as a criterion for good discrimination.

Using the ROC analyses, we selected the best cut-off score for the PPT test when used on its own and for each of the combined scores (the most efficient had an AUC > 0.8 using a smaller number of covariates). The best cut-off score was the value in which sensitivity + specificity - 1 was maximized. Using these cut-off scores, the following values were calculated: sensitivity (Se), specificity (Sp), positive likelihood ratio $(\mathrm{LR}+$ ) and negative likelihood ratio (LR-).

The calculation of the sample size was based on the general rule that 15 subjects per predictor are necessary for a reliable equation in multivariate regression models. ${ }^{13} \mathrm{~A}$ minimum of 75 participants were recruited assuming a maximum of five determinants. All the analyses were performed using the SPSS version 19.0 software (IBM Corp., Chicago, IL, USA). 
Table 1 Descriptive data of tendons with patellar tendinopathy and healthy tendons and comparison between the dominant and non-dominant side

\begin{tabular}{|l|l|l|l|l|}
\hline & & PT & Healthy & Difference mean PT-healthy (95\% Cl) \\
\hline Dominant leg & $\mathrm{N}$ & 12 & 61 & \\
\hline & PPT (kg) & $9.3(3.1)$ & $10.4(2.5)$ & $1.1(-0.5$ to 2.8$)$ \\
\hline & VISA-P (points) & $69.7(8.7)$ & $97.2(4.7)$ & $27.5(21.8 \text { to } 33.1)^{*}$ \\
\hline & VAS (cm) & $3.7(3.3)$ & $0.4(0.9)$ & $-3.3(-5.4 \text { to }-1.2)^{*}$ \\
\hline Non-dominant leg & $\mathrm{N}$ & 8 & 65 & \\
\hline & PPT (kg) & $7.2(3.4)$ & $10.7(2.5)$ & $3.5(1.5 \text { to } 5.5)^{* *}$ \\
\hline & VISA-P (points) & $73.0(5.8)$ & $97.2(4.5)$ & $24.2(20.8 \text { to } 27.6)^{* *}$ \\
\hline & VAS (cm) & $3.7(2.1)$ & $0.3(0.9)$ & $-3.7(-5.1 \text { to }-1.6)^{* *}$ \\
\hline
\end{tabular}

The data are provided as the mean (standard deviation) unless the opposite is indicated ${ }^{*} p<0.05^{* *} p<0.01$.

Abbreviations: $\mathrm{Cl}$, confidence interval; PPT, pain pressure threshold; PT, patellar tendinopathy; VAS, visual analogue scale; VISA-P, Victorian Institute of Sport Assessment, Patellar tendon questionnaire.

\section{Results}

Of the 75 initial players in the study, 2 were excluded due to previous knee surgeries. Finally, 73 players were included in the study, and 146 patellar tendons were analyzed. The mean age of patients was 26.8 years (standard deviation [SD] 4.8); the mean height was $198.1 \mathrm{~cm}(\mathrm{SD}=8.4)$; the mean weight was $95.5 \mathrm{~kg}(\mathrm{SD}=11.4)$ and the mean body mass index was $24.3 \mathrm{~kg} / \mathrm{m}^{2}(\mathrm{SD}=1.6)$. All athletes were able to both train and compete.

In total, 20 tendons (13.17\% of the 146 students) were diagnosed with PT and the 126 remaining tendons were used as controls. No players presented PT in both knees at the time of the study. Both the dominant and non-dominant knee were analyzed separately for the descriptive analysis. In both cases, either on the dominant side or the non-dominant side, the values of the VISA-P and VAS of the tendons with PT were significantly different from those of the healthy tendons. However, the PPT values of the knees with PT were only significantly lower than the healthy tendons on the nondominant side (-Table $\mathbf{1}$ ).

\section{Determinants of the PPT Values}

The multivariate predictive models of the PPT values on both sides (dominant and non-dominant side) were statistically significant $(p<0.05$ ) accounting for $17.8 \%$ and a $23.1 \%$ of the variance (R2), respectively (-Table $\mathbf{2}$ ). The height was positively associated both with the dominant and the nondominant sides, describing a similar percentage of the variance (partial R2), 8.8\% and 7.2\%, respectively. The VAS score was negatively associated on both sides, accounting for $7.9 \%$ of the variance on the dominant side and $16 \%$ on the nondominant side.

\section{Discriminatory Accuracy of the Test on its Own or Combined}

The ROC and AUC of the PPT test on its own and the combined values of the covariates are shown in -Fig. 1. The AUC for the PPT test was only 0.713 (95\% CI 0.5870.840 ), and when it was combined with the significant covariates (height and VAS), this increased considerably until 0.867 (95\% CI 0.759-0.975). The combined values of the PPT with the VAS alone also offered a greater increase until 0.852 (95\% CI 0.732-0.973). The AUC of the complete combined values, without the VAS value, was 0.717 , which means that the VAS test adds a high value as a discriminatory marker of PT. Based on these results, we calculated an optimal cut-off point for the test performed on its own or combined with the VAS score. The cut-off point for a more precise discrimination of a tendon with PT was $8.8 \mathrm{~kg}$ for the PPT on its own and $14 \%$ for the PPT combined with the VAS. The use of the equation

Table 2 Multivariate linear regression model including determinants for the pain pressure threshold scores in both the dominant and non-dominant sides

\begin{tabular}{|c|c|c|c|c|c|c|c|}
\hline Side & Independent variable & Estimate & SD & B standardized & $P$-value & $\mathrm{R}^{2}$ model & $\mathrm{R}^{2}$ partial \\
\hline \multicolumn{6}{|c|}{ Dominant } & $17.8 \%$ & \\
\hline & Height $(\mathrm{cm})$ & 0.09 & 0.04 & 0.29 & 0.008 & & $8.8 \%$ \\
\hline & VAS score & -0.38 & 0.15 & -0.28 & 0.012 & & $7.9 \%$ \\
\hline \multicolumn{6}{|c|}{ Non-dominant } & $23.1 \%$ & \\
\hline & Height (cm) & 0.09 & 0.04 & 0.27 & 0.013 & & $7.2 \%$ \\
\hline & VAS score & -0.76 & 0.20 & -0.40 & 0.000 & & $16 \%$ \\
\hline
\end{tabular}

Abbreviations: SD, standad error; VAS, visual analogue scale. 


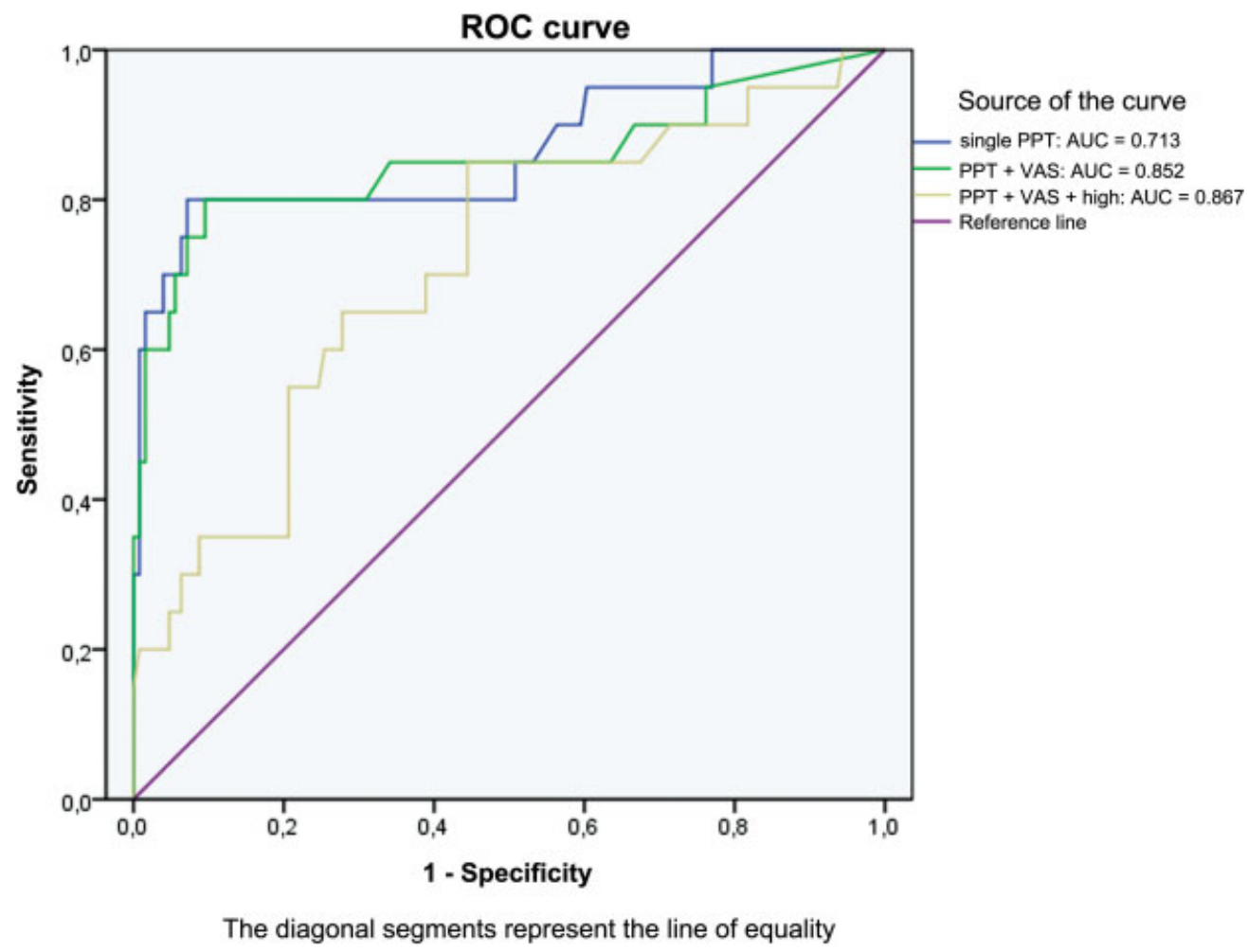

Fig. 1 Receiver-operating characteristic (ROC) curves, with the area under the ROC curve (AUC), calculated for the pain pressure thresholds (PPTs) alone and with the predictive probability combining the test and its covariates to determine patellar tendinopathy. Abbreviations: VAS, visual analogue scale.

$$
p=\frac{1}{1+e^{-(-1.99-0.12 U D P+0.93 E V A)}}
$$

introducing the PPT and VAS values enables the possibility to obtain the probability as a prognosis of the combined prognosis; therefore, if this is superior or equal to 0.14 , a PT may be diagnosed. The ratios of sensitivity, specificity and probability calculated for these cut-off points are shown in - Table 3.

\section{Discussion}

According to the information available, this is the first study to describe the PPT value of professional basketball players with,

Table 3 Exactness of the pain pressure threshold scores and the predictive probabilities of the combination with the visual analogue scale score

\begin{tabular}{|l|l|l|}
\hline Measures & PPT \\
\hline & PPT scores & Combined values PPT + VAS \\
\hline Sensitivity & 71.4 & 80 \\
\hline Specificity & 55.5 & 90.5 \\
\hline LR+ & 1.59 & 8.42 \\
\hline LR- & 0.52 & 0.219 \\
\hline
\end{tabular}

a. The cut-off point for the test on its own was $8.8 \mathrm{Kg}$. b. The cut-off point for the combined value was $14 \%$. The probability of having a tendon with patellar tendinopathy using the PPT and VAS scores was calculated using the following equation: $1+1+e^{-(-1.99-0.12(p m)+0.99(\mathrm{VAS}) \text { ) }}$

Abbreviations: PPTs, pain pressure threshold; VAS, visual analogue scale. and without, PT. Our results reveal that the height and the values of the VAS are determining factors of the PPT values, and that the PPT does not enable the possibility to precisely discriminate between knees with, and without, PT on its own. However, the discriminative capacity and, therefore, the diagnostic value of the PPT can be notably improved when it is combined with the VAS covariate. In this study, we found that the PPT values did not differ when comparing the dominant leg of players with PT with the values of the dominant leg in players without PT. The height had the best predictive capacity on the dominant side (8.8\% and $7.2 \%$ ), whereas the VAS value had a greater predictive value in the non-dominant side (7.9\% and 16\%). Speculatively, these results can be related with adaptations in the mechanisms of pain modulation on the dominant side, in which one would expect more use of the same and, therefore, the existence of a greater number of muscle contractions able to modulate pain. ${ }^{14,15}$

Clinically, the optimal cut-off point for the PPT necessary in order to consider the diagnosis of PT was $8.8 \mathrm{~kg}$ and $14 \%$ for the combined scores using the PPT and the VAS. Although these were the cut-off points for the diagnosis of PT, the performance of a correct diagnosis necessarily requires this information to be combined with other clinical evidence.

In our sample, we identified 20 tendons with PT and 126 healthy knees (20 athletes with PT compared to 53 healthy athletes), representing a prevalence of $37.7 \%$ with tendinopathy, slightly higher than the results obtained by Lian et al, who reported a prevalence of $31.9 \%$ among elite players. ${ }^{4}$ However, a study by Zwerver et $\mathrm{al}^{3}{ }^{3}$ in non-elite athletes, found a prevalence of PT ranging between 2.5 and $14.4 \%$, 
depending on the sport they were performing, Cook et al found that, among adult basketball players, this was $11.8 \%$, whereas among junior basketball players under the age of 18 , the prevalence was $7 \% .{ }^{16}$ The differences in the results of our study can be explained by the characteristics of the sample, as we included professional basketball players, who have significant load requirements.

At present, it is not possible to affirm the existence of a direct relationship between image assessment (ultrasound and magnetic resonance) and the symptoms of PT. Furthermore, there is no relationship between the amount of pain and the degree of vascularization. ${ }^{17}$ However, previous studies show that algometry is a valid and reliable tool in the diagnosis of PT. ${ }^{9}$ Besides, the PPT has proven to be the most reliable method for the assessment of sensitivity to pain, compared with other methods, such as palpation or the VAS. ${ }^{18}$ Notwithstanding, the cut-off point for the different parts of the body should be calculated to enable us to perform a more specific assessment. ${ }^{19}$ Likewise, each population should have their own cut-off point, as occurs with the professional basketball players in our study. Sensitivity to pain is not a uniform characteristic; ${ }^{20}$ therefore, it is necessary to know the pain threshold of professional basketball players in order to use this as a diagnostic test in this population. Regarding algometry, Kregel et $\mathrm{al}^{8}$ described a mean PPT of $2.2 \mathrm{~kg} / \mathrm{cm}^{2}$ in the PT of university sportsmen, which is much lower than our result of $8.8 \mathrm{~kg} / \mathrm{cm}^{2}$ found in the same tendon. We think that these data highlight the importance of using specific values for professional basketball players.

The PPT test was unable to effectively discriminate the presence of PT in professional basketball players because the values of $L R+(1.59)$ and $L R-(0.52)$ were poor $(L R+<2$ and LR- > 0.50), despite having obtained an AUC higher than 0.7. The accuracy was greater and positively improved with the inclusion of the VAS covariate. When this occurs, the accuracy of a test depends on another covariate, and it is commonplace to adjust to these variables in the statistical analysis. ${ }^{21}$ Even so, according to our information, our study is the first to assess the influence of covariates in the discriminatory accuracy of the PPT test. Although the adjustment of the covariates is routine in other medical areas, this issue is not extensively assessed as of yet in the functional tests used in sports medicine. Neither is it common in therapeutic and etiological studies, as it has received little attention in the development of markers for tests or diagnoses. ${ }^{13}$ Our study has focused on this aspect, therefore contributing to redefining our understanding regarding the way functional tests can be used in a combined manner in professional players.

\section{Study Limitations}

The gold standard diagnosis of PT was based on a questionnaire (VISA-P) and tenderness to palpation at the inferior pole of the patella performed by a physical therapist. An image-based diagnosis was not performed, which, however, could have provided relevant information for the definition of the clinical diagnosis and categorization of the type of tendinopathy. However, many studies have included patients with $\mathrm{PT}^{7,16}$ via a self-report questionnaire. Furthermore, although we have found determinants of the PPT that improve the discrimination between knees with, or without, PT, it is possible that other factors not considered in our study (for example, gender) may increase the discriminative capacity of this test. Lastly, this study only included players who were able to compete; therefore, the prevalence of PT may have been lower than in other studies. Besides, the accuracy of the diagnosis could have improved if the study had been performed on the whole team, without ruling out those who could not compete.

Future studies could analyze the behavior of these same tests and the influence of covariates in the female population, as our study was limited to a male population with the aim of avoiding bias due to the existing differences between the genders regarding the mechanisms of pain modulation. Furthermore, in this study, we researched the pain that PT produces at a certain point in time; therefore, future research should prospectively control and compare the levels of pain throughout the season.

\section{Conclusions}

The present study shows that the measurement of the PPT in the patellar tendon is not recommended to be performed on its own for discriminating the presence of PT in professional basketball players. However, when a cluster of the PPT and the VAS is used for the diagnosis of PT in professional players, the diagnostic accuracy increases considerably. Due to the good values of the LR + obtained by the PPT and VAS cluster for the diagnosis of PT, and the ease of its application, the combined use of these variables is recommended for performing a clinical diagnosis of PT in professional basketball players.

\section{Funding}

This research received no specific grant from any funding agency in the public, commercial, or not-for-profit sectors.

\section{Conflicts of Interest}

The authors have no conflicts of interest to declare.

\section{References}

1 Danielson P, Alfredson H, Forsgren S. Immunohistochemical and histochemical findings favoring the occurrence of autocrine/ paracrine as well as nerve-related cholinergic effects in chronic painful patellar tendon tendinosis. Microsc Res Tech 2006;69 (10):808-819

2 Rudavsky A, Cook J. Physiotherapy management of patellar tendinopathy (jumper's knee). J Physiother 2014;60(03):122-129. Doi: $10.1016 /$ j.jphys.2014.06.022

3 Zwerver J, Bredeweg SW, van den Akker-Scheek I. Prevalence of Jumper's knee among nonelite athletes from different sports: a cross-sectional survey. Am J Sports Med 2011;39(09):1984-1988. Doi: $10.1177 / 0363546511413370$

4 Lian ØB, Engebretsen L, Bahr R. Prevalence of jumper's knee among elite athletes from different sports: a cross-sectional study. Am J Sports Med [Internet] 2005;33(04):561-567http:// journals.sagepub.com/doi/abs/10.1177/0363546504270454

5 Ramos LA, Carvalho RT, Garms E, Navarro MS, Abdalla RJ, Cohen M. Prevalence of pain on palpation of the inferior pole of the 
patella among patients with complaints of knee pain. Clinics (São Paulo). scielo 2009;64(03):199-202

6 Rutland M, O'Connell D, Brismée J-M, Sizer P, Apte G, O'Connell J. Evidence-supported rehabilitation of patellar tendinopathy. N Am J Sports Phys Ther 2010;5(03):166-178

7 Cook JL, Khan KM, Kiss ZS, Purdam CR, Griffiths L. Reproducibility and clinical utility of tendon palpation to detect patellar tendinopathy in young basketball players. Victorian Institute of Sport tendon study group. Br J Sports Med 2001;35(01):65-69

8 Kregel J, van Wilgen CP, Zwerver J. Pain assessment in patellar tendinopathy using pain pressure threshold algometry: an observational study. Pain Med 2013;14(11):1769-1775

9 van Wilgen P, van der Noord R, Zwerver J. Feasibility and reliability of pain pressure threshold measurements in patellar tendinopathy. J Sci Med Sport 2011;14(06):477-481

10 Visentini PJ, Khan KM, Cook JL, Kiss ZS, Harcourt PR, Wark JD; Victorian Institute of Sport Tendon Study Group. The VISA score: an index of severity of symptoms in patients with jumper's knee (patellar tendinosis). J Sci Med Sport 1998;1(01):22-28

11 Hernandez-Sanchez S, Hidalgo MD, Gomez A. Cross-cultural adaptation of VISA-P score for patellar tendinopathy in Spanish population. J Orthop Sports Phys Ther 2011;41(08):581-591

12 Hosmer DW, Lemeshow S, Sturdivant RX. Applied Logistic Regression [Internet]. Wiley; 2013. (Wiley Series in Probability and Statistics). Available from: https://books.google.es/books?id=64] YAwAAQBAJ

13 Tabachnick BG, Fidell LS. Using Multivariate Statistics [Internet]. Pearson; 2013. (Always learning). Available from: https://books. google.es/books?id=2KJIngEACAAJ
14 Rio E, van Ark M, Docking S, et al. Isometric Contractions Are More Analgesic Than Isotonic Contractions for Patellar Tendon Pain: An In-Season Randomized Clinical Trial. Clin J Sport Med 2017;27 (03):253-259

15 Rio E, Kidgell D, Purdam C, et al. Isometric exercise induces analgesia and reduces inhibition in patellar tendinopathy. $\mathrm{Br} \mathrm{J}$ Sports Med 2015;49(19):1277-1283

16 Cook JL, Khan KM, Kiss ZS, Griffiths L. Patellar tendinopathy in junior basketball players: a controlled clinical and ultrasonographic study of 268 patellar tendons in players aged $14-18$ years. Scand J Med Sci Sports [Internet] 2000;10(04):216-220. Doi: 10.1034/j.1600-0838.2000.010004216.x

17 De Jonge S, Warnaars JLF, De Vos RJ, et al. Relationship between neovascularization and clinical severity in Achilles tendinopathy in 556 paired measurements. Scand J Med Sci Sports 2014;24(05): $773-778$

18 Sayed-Noor AS, Englund E, Wretenberg P, Sjödén GO. Pressurepain threshold algometric measurement in patients with greater trochanteric pain after total hip arthroplasty. Clin J Pain 2008;24 (03):232-236

19 Tastekin N, Uzunca K, Sut N, Birtane M, Mercimek OB. Discriminative value of tender points in fibromyalgia syndrome. Pain Med 2010;11(03):466-471

20 Nielsen CS, Stubhaug A, Price DD, Vassend O, Czajkowski N, Harris JR. Individual differences in pain sensitivity: genetic and environmental contributions. Pain 2008;136(1-2):21-29

21 Janes H, Pepe MS. Adjusting for covariates in studies of diagnostic, screening, or prognostic markers: an old concept in a new setting. Am J Epidemiol 2008;168(01):89-97 